\title{
Costs of managing castrate-resistant metastatic prostate cancer patients at Inkosi Albert Luthuli Central Hospital
}

\author{
NC Gabela, ${ }^{1,3}$ (D) S Bhadree, ${ }^{2}$ LJ Mathibe ${ }^{3}$ (D) \\ ${ }^{1}$ NTP Radioisotopes Pty (Ltd), South Africa \\ ${ }^{2}$ Oncology Department, Inkosi Albert Luthuli Central Hospital, Durban, South Africa \\ ${ }^{3}$ Discipline of Pharmaceutical Sciences, Nelson R Mandela School of Medicine, University of KwaZulu-Natal, South Africa
}

Corresponding author, email: mathibel@ukzn.ac.za

Background: Metastatic castration-resistant prostate cancer (mCRPC) has a five-year survival rate of $30 \%$ despite the availability of expensive therapeutic agents. This study investigated the costs to a tertiary public hospital of the management of mCRPC with various therapeutic agents.

Methods: Between 1 January 2017 and 24 November 2019 the records of patients who were diagnosed with mCRPC and received chemotherapy (docetaxel) in combination with goserelin (a luteinising hormone-releasing hormone [LHRH]), or bicalutemide (an anti-androgen) at the Inkosi Albert Luthuli Central Hospital were analysed. The activity-based costing (ABC) model was used to calculate the medicine costs and other expenses incurred by the hospital.

Results: During the study period, 64 patients, mean age 66 years $( \pm 8.7)$ at first visit, met the inclusion criteria of this study. The total cost incurred by the hospital was R10 338 559. On average, a total of R161 540 (SEM R22 699.00) per patient was incurred by the hospital. There was $60 \%$ reduction $(p=0.01)$, after the average period of 4 months $( \pm 2.9)$, in PSA levels in patients who received goserelin monotherapy.

Conclusion: The therapeutic gain from extremely expensive therapy in mCRPC patients requires evaluation of clinical response and survival data to justify the expense.

Keywords: prostate cancer, prostate-specific antigen, chemotherapy, activity-based costing

\section{Introduction}

The South African Medical Research Council (SAMRC) reported that in 2012 cancer was the fifth leading cause of death in South Africa, causing $8.7 \%$ of all reported deaths. ${ }^{1}$ Prostate cancer (PCa) has the second highest frequency of all cancers, although local data is insufficient due to under-reporting of PCa cases in particular. ${ }^{2}$ Histologically adenocarcinoma accounts for $90 \%$ of cases PCa and occurs most commonly in men above 50 years of age. In South Africa, PCa is a leading organ-specific cancer in males, with 12452 new cases diagnosed in $2018 .^{3}$ The prostatespecific antigen (PSA) blood test and a digital rectal examination are the recommended screening tools for $\mathrm{PCa}$, indicating the need for a prostate biopsy. The PSA level is further used to prognosticate and to guide the choice of appropriate management. ${ }^{3,4}$ Depending on their risk stratification, staging and grading of the $\mathrm{PCa}$, patients are either placed on surveillance by means of 'watchful waiting' or 'active surveillance', or they are offered treatment. Curative treatment options include surgery (radical prostatectomy) and/or radiation therapy (external beam and/ or brachytherapy). ${ }^{5,6}$ Patients with advanced or metastatic disease may be managed with a variety of treatments depending on several factors including the extent of disease, their comorbidities and functional status as well as hospital resources. Treatment options include hormonal agents (antiandrogens and LHRH agonists), chemotherapy (docetaxel), palliative radiation therapy and supportive care. ${ }^{7}$ The aim of these treatments, therefore, is to improve the progressionfree survival and overall survival of patients in addition to improving their quality-of-life parameters.

The cost of treatment of PCa has been identified as the main driver of the economic burden due to this disease, globally. ${ }^{8,9}$ In South Africa, Heyns and colleagues reported that the use of bilateral orchiectomy, as compared to androgen deprivation therapy (luteinising hormone-releasing hormone analogue [LHRHa] and/or bicalutamide) in patients diagnosed with advanced PCa, from January 1996 to December 2007, resulted in a saving of ZAR24 $321000 .{ }^{10}$ However, there have been no recent studies that have investigated the overall/total costs associated with management of metastatic castrate-resistant prostate cancer (mCRPC) in South Africa. About $20 \%$ of PCa patients develop mCRPC within 5 years of hormonal ablation therapy. ${ }^{11}$ Therefore, this study investigated the overall costs incurred by a tertiary public hospital for the management of MCRPC with standard chemotherapy regimens. 


\section{Methods}

This was a retrospective, descriptive study conducted on patients' electronic records at the Inkosi Albert Luthuli Central Hospital (IALCH) in Durban, South Africa. IALCH is a public/private partnership tertiary/quaternary 840bed hospital. Patients are referred from other hospitals in KwaZulu-Natal (KZN) province by telephonic/electronic booking systems. PCa patients are seen in a weekly combined urology-oncology clinic. New patient waiting time is approximately 3-6 weeks, with an average of 30-40 new patients monthly.

The files of patients who were diagnosed with metastatic PCa and had received chemotherapy in combination with goserelin and/or bicalutamide (at standard recommended doses) between 1 January 2017 and 24 November 2019 were identified. Patient data were extracted using the hospital's MediTech $^{\text {TM }}$ paperless/electronic information technology (IT) system. The activity-based costing (ABC) model, as was validated at other similar settings, was utilised to calculate the cost incurred by the hospital. ${ }^{12}$ Briefly, this costing model sources data from various hospital information systems with various predetermined relationships and calculations. The direct costs would include medicines and laboratory investigations. Indirect costs are distributed to locations and services primarily by clinical volumes or cost drivers. For example, indirect costs include telephone and electricity bills, medical equipment, doctors, paramedical services such as physiotherapy, IT equipment, cleaning and porter services, patient registrations, human resource and financial services, as well as patient catering. In a ward, the activity that drives the cost is usually inpatient days. Therefore, the inpatient days or occupancy would be the cost driver.

Data were captured on Microsoft ${ }^{\circledR}$ Excel, and GraphPad Prism programme was used for bivariate statistical analyses and to determine the quantitative measures of dependence (such as the Spearman's r correlation). Statistical significance for categorical variables was tested using the chi-square test with Yates correction. Descriptive statistics for frequencies, means and standard deviations (SD) or standard error of the mean (SEM) error bars, medians and interquartile range (IQR), and 95\% confidence intervals (CI) where applicable were used. Differences with $p$-values less than 0.05 were considered significant. Further, the Cohen's d (and equation) was used to determine the effect sizes to inform clinical significance beyond the statistical significance which the $p$-values provide.

\section{Results}

Of the 327 patients with malignant neoplasm of the prostate, 64 received hormonal and/or chemotherapy for mCRPC. Their average age was 66 years $( \pm 8.7)$ at first visit. The majority, 59\% $(n=38)$, of patients where Black; 25\% $(n=16)$, and $13 \%(n=8)$ were Indians and Whites, respectively. There was also one Coloured patient as well as one patient whose race could not be determined from the records. At first visit, the PSA levels ranged from 0.01 to $1997.0 \mathrm{ng} / \mathrm{ml}$ with median levels of $19.06 \mathrm{ng} / \mathrm{ml}$ (IQR $1.4-160.2 \mathrm{ng} / \mathrm{ml})$.

The total cost incurred by the hospital for management of $64 \mathrm{mCRPC}$ patients during the period of this study was

Table I: Hormonal therapy, chemotherapy and pain management medicines administered to patients

\begin{tabular}{|c|c|c|c|c|}
\hline $\begin{array}{l}\text { Chemotherapy, hormonal therapy } \\
\text { drugs/regimens and other medicines }\end{array}$ & $n(\%)$ & $\begin{array}{l}\text { Mean age in } \\
\text { years }\end{array}$ & Doses/cycles & $\begin{array}{l}\text { Spearman's r ( } p \text {-values) of mean } \\
\text { age of goserelin group vs others }\end{array}$ \\
\hline Goserelin & $40(63 \%)$ & $63(\mathrm{SD} 7.5)$ & 140 & - \\
\hline Bicalutamide & $27(42 \%)$ & $66(\mathrm{SD} 7.6)$ & 107 & $0.3(p=0.18)$ \\
\hline Docetaxel & $17(27 \%)$ & $64(\mathrm{SD} 6.9)$ & 100 & $0.4(p=0.16)$ \\
\hline $\begin{array}{l}\text { Goserelin + bicalutamide }+ \\
\text { docetaxel }\end{array}$ & $7(11 \%)$ & $66(\mathrm{SD} 8.5)$ & 94 & $0.3(p=0.54)$ \\
\hline Cyproterone acetate & $6(9 \%)$ & 65 (SD 5.4) & 14 & - \\
\hline Vinorelbine & 1 & - & 12 & - \\
\hline $\begin{array}{l}\text { Other chemotherapy (vincristine, } \\
\text { 5-fluoro-uracil, cisplatin, doxorubicin, } \\
\text { dactinomycin monotherapies) }\end{array}$ & 5 & & 1 dose for each patient & \\
\hline Paracetamol packs of $100 \mathrm{~s}$ & $44(69 \%)$ & $66(\mathrm{SD} 7.3)$ & 224 & - \\
\hline Ibuprofen packs of $84 \mathrm{~s}$ & $7(11 \%)$ & $64(\mathrm{SD} 8.0)$ & 10 & \\
\hline Morphine & $18(28 \%)$ & $64(\mathrm{SD} 8.0)$ & 36 & - \\
\hline Amitriptyline packs of $28 \mathrm{~s}$ & $12(19 \%)$ & $63(\mathrm{SD} 7.8)$ & 22 & - \\
\hline Amitriptyline + morphine & $6(9 \%)$ & $64(\mathrm{SD} 7.5)$ & 27 packs of $28 s+27$ doses & - \\
\hline
\end{tabular}

Table II: PSA levels in patients treated with main hormonal therapy and chemotherapy regimens

\begin{tabular}{lcccc}
\hline $\begin{array}{l}\text { Main chemotherapy } \\
\text { and hormonal therapy } \\
\text { regimens }\end{array}$ & $\begin{array}{c}\boldsymbol{n} \text {; mean age in } \\
\text { years (SD) }\end{array}$ & $\begin{array}{c}\text { Median PSA levels } \\
\text { (at 1st visit) in ng/mL } \\
\text { (IQR) }\end{array}$ & $\begin{array}{c}\text { Median PSA change between last } \\
\text { and 1st visits (IQR) }\end{array}$ & $\begin{array}{c}\text { Mean period, } \\
\text { in months } \\
\text { (SD) }\end{array}$ \\
\hline Goserelin & $7 ; 72(8.3)$ & $9.8(0.5-176.8)$ & $-5.9(-67.0--0.14) ; p=0.01 ; 60 \% \downarrow$ & $4(2.9)$ \\
Goserelin + bicalutamide & $12 ; 66(8.5)$ & $11.2(0.32-104.1)$ & $-0.1(-12.8-65.1) ; p=0.05 ; 1 \% \downarrow$ & $13(8.8)$ \\
$\begin{array}{l}\text { Goserelin + bicalutamide }+ \\
\text { docetaxel }\end{array}$ & $5 ; 68(9.3)$ & $5.4(1.8-59.7)$ & $45.6(18.45-446.1) ; p>0.05 ; 844 \% \uparrow$ & $23(12.5)$ \\
Docetaxel & $4 ; 62(3.0)$ & $174.3(59.7-962.9)$ & $8.1(-91.7-169.5) ; p>0.05 ; 5 \% \uparrow$ & $7(4.6)$
\end{tabular}


R10 338559.00 (this was equivalent to 544134 USD; $1 \mathrm{USD}=19$ ZAR on 31 January 2020). On average, a total of R161 540.00 (SEM R22 699.00) per patient was incurred by the hospital. In particular, the hospital incurred the average cost of R5 477.00 (SEM R889.00) for therapy cycle per patient.

Sixty-three per cent $(n=40)$ of patients, were treated with goserelin alone or in combination with chemotherapy drugs, while $42 \%(n=27)$ and $27 \%(n=17)$ were treated with bicalutamide and docetaxel (as monotherapy or in combination with other chemotherapy drugs), respectively. As shown in Table I, only $10 \%(n=7)$ of patients were treated with goserelin, bicalutamide and docetaxel. There were no significant $(p>0.05)$ correlations between patient age at first visit and the choice of chemotherapy regimens. For pain management, morphine was more likely to be used as monotherapy than in combination with amitriptyline (odds ratio [OR] 3.1; 95\% CI 1.1-8.2; $p<0.03$ ).

Although there was a $60 \%$ reduction $(p<0.01)$, after the average period of four months (SD 2.9), in PSA levels, median change of $-5.7 \mathrm{ng} / \mathrm{ml}$ (IQR -67.0 to -0.14 ), with patients who received goserelin, the effect size was greater than 0.8 (Cohen's d 1.03). Meaning, there were large variations among patients for this reduction to be clinically significant. The change in PSA levels in other groups (as shown in Table II) were inconclusive to be used as surrogate markers for assessing the effectiveness of chemotherapy. This was because there were insufficient records on mortality to reasonably assess the survival rates. Sixty-three per cent $(n=40)$ of patients were treated with radiotherapy in addition to chemotherapy.

\section{Discussion}

The findings of this study, which was the first to quantify the costs incurred by a primarily public hospital in South Africa, indicate that the management of patients with $\mathrm{mCRPC}$ is complex and very costly. There were no published studies for direct comparison with the findings of the current research. However, the reports on cost of management of mCRPC patients in other settings in South Africa and globally provide an opportunity for comparison. In Italy, the cost of drug treatment represented more than $77 \%$ of the economic burden of the management of mCRPC. ${ }^{8}$ Recent estimates of the cost of drug treatments of mCRPC in Canadian public healthcare settings indicated that the mean cost of mCRPC drug treatments over an average period of 28 months was $\$ 48428(1 \mathrm{CAD}=10.15$ on 31 January 2020$){ }^{7}$ Therefore, other management approaches have been explored in order to save costs. Also, the findings of Heyns and colleagues showed that treating mCRPC with surgical castration (bilateral orchiectomy) instead of androgen suppression chemotherapy, at a tertiary academic and public hospital in South Africa, was associated with cost saving of over R35 000 per patient per year - with no significant difference in PSA levels and mortality at last follow-up. ${ }^{10,13}$ The current study reported an average total expenditure of R161 540 (SEM R22 699) per mCRPC patients with 60\% reduction $(p=0.01)$, after the average period of four months $( \pm 2.9)$, in PSA levels in patients who received goserelin therapy.

The use of PSA levels for PCa screening purposes is more controversial than when used for prognosis and as a surrogate marker for the assessment of the effectiveness of therapy. Therefore, it is recommended that reliable estimation of clinically-significant changes in PSA levels requires follow-up for at least 2 years due to substantial physiological variation in serum PSA. ${ }^{14}$ In contrast, the findings of this study indicate that even after 2 years of follow-up, the serum PSA levels were still exceedingly variable with IQRs of -91.7 to 169.5 and 18.45 to $446.1 \mathrm{ng} /$ $\mathrm{ml}$ in mCRPC patients treated with docetaxel (for a mean period of 7 months) and a triple regimen therapy (goserelin + bicalutamide + docetaxel, for a mean period of 23 months), respectively. A PSA velocity (PSAV), which is a longitudinal assessment of PSA, instead of a single PSA measurement is recommended. ${ }^{14}$ A PSAV decline of $\geq 50 \%$ is a more reliable predictor of survival regardless of treatment, instead of achievement of the nadir serum PSA level of $4 \mathrm{ng} / \mathrm{ml} .{ }^{15,16}$

This study was based only on patients' electronic records and therefore, mortality and details of clinical assessments could not be retrieved. This has highlighted the need for a multidisciplinary, prospective and longitudinal follow-up study to justify the cost of this extremely expensive mCRPC therapy by assessing the therapeutic gain by evaluating clinical and biochemical response and survival data.

Patients who achieved a PSA decline of $\geq 50 \%$ had better survival than those who did not, regardless of treatment.

\section{Acknowledgements}

The authors would like to acknowledge the clinicians and non-medical staff at the IALCH Medical Oncology and Nuclear Medicine departments for their assistance during the data collection stage. In particular, thank you to Mrs Tanya Francis, at the IALCH's Annually Managed Expenditure (AME) Healthcare Africa Information Technology department for tuition on the $\mathrm{ABC}$ model and for assisting with downloading of information that met the inclusion criteria of this study from the hospital's vast records.

\section{Conflict of interest}

The authors declare no conflict of interest.

\section{Funding source}

NTP Radioisotopes provided funds for NCG to pay for the travelling and lodging expenses during data collection phase.

\section{Ethical approval}

The study proposal and subsequent annual re-certifications were approved by the University of KwaZulu-Natal Biomedical Research Ethics Committee (Ref.: BE458/18); KwaZulu-Natal Department of Health as well all applicable authorities/head of departments at the IALCH.

\section{ORCID}

NC Gabela (iD) https://orcid.org/0000-0001-5489-6840 LJ Mathibe (iD https://orcid.org/0000-0003-4739-8944

\section{REFERENCES}

1. Adeloye D, David RA, Aderemi AV, et al. An estimate of the incidence of prostate cancer in Africa - a systematic review and meta-analysis. PLoS ONE. 2016;11(4):e0153496. https:// doi.org/10.1371/journal.pone.0153496.

2. Singh E, Underwood JM, Nattey C, et al. South African National Cancer Registry: Effect of withheld data from private health systems on cancer incidence estimates. S Afr Med J. 2015;105(2):107-9. https://doi.org/10.7196/SAMJ.8858. 
3. Ilic D, Djulbegovic M, Jung JH, et al. Prostate cancer screening with prostate-specific antigen (PSA) test - a systematic review and meta-analysis. BMJ. 2018;362:k3519. https://doi.org/10.1136/bmj.k3519.

4. Anderson D, Barner R, Bida M, et al. Prostate Cancer Diagnostic and Treatment Guidelines. The Prostate Cancer Foundation of South Africa. 2013. Available from: http:// prostate-ca.co.za/wp-content/uploads/2017ProstateGuideline sDraftVersion2016.pdf. Accessed 2 Jan 2021.

5. Cuccurullo V, Di Stasio GD, Mansi L. Nuclear medicine in prostate cancer - a new era for radiotracers. World J Nucl Med. 2018;17(2):70-8.

6. DeVita VT, Lawrence TS, Rosenberg SA. Cancer: Principles \& Practice of Oncology, 10th ed. Wolters Kluwer: Philadelphia; 2015. p 932-79.

7. Dragomir A, Dinea D, Vanhuyse M, et al. Drug costs in the management of metastatic castration-resistant prostate cancer in Canada. BMC Health Serv Res. 2014;14:252. https://doi. org/10.1186/1472-6963-14-252.

8. Restelli U, Ceresoli GL, Croce D, et al. Economic burden of the management of metastatic castrate-resistant prostate cancer in Italy - a cost of illness study. Cancer Manag Res. 2017;9:789-800. https://doi.org/10.2147/CMAR.S148323.

9. Flannery K, Drea E, Hudspeth L, et al. Budgetary impact of cabazitaxel use after docetaxel treatment for metastatic castration-resistant prostate cancer. J Manag Care Spec Pharm. 2017;23(4):416-26. https://doi.org/10.18553/jmcp.2017.23.4. 416.
10. Heyns CF, Basson J, Van der Merwe A, et al. Clinical (nonhistological) diagnosis of advanced prostate cancer - evaluation of treatment outcome after androgen deprivation therapy. S Afr J Surg. 2014;52(3):82-5. https://doi.org/10.7196/sajs.1689.

11. Pollard ME, Moskowitz AJ, Diefenbach MA, Hall SJ. Costeffectiveness analysis of treatments for metastatic castrationresistant prostate cancer. Asian J Urol. 2017;4:37-43. https:// doi.org/10.1016/j.ajur.2016.11.005.

12. Javid M, Hadian M, Ghaderi H, et al. Application of the activity-based costing method for unit-cost calculation in a hospital. Glob J Health Sci. 2015;17;8(1):165-72. https://doi. org/10.5539/gjhs.v8n1p165.

13. Norum J, Nieder C. Treatments for metastatic prostate cancer (mPC) - a review of costing evidence. Pharmacoeconomics. 2017;35(12):1223-36. https://doi.org/10.1007/s40273-0170555-8.

14. Stenman UH, Abrahamsson PA, Aus G, et al. Prognostic value of serum markers for prostate cancer. Scand J Urol Nephrol Suppl. 2005;216:64-81. https://doi.org/10.1080/ 03008880510030941.

15. Fitzpatrick JM, Banu E, Oudard S. Prostate-specific antigen kinetics in localised and advanced prostate cancer. BJU Int. 2009;103(5):578-87. https://doi.org/10.1111/j.1464-410X. 2009.08345.x.

16. Kelly WK, Scher HI, Mazumdar M, et al. Prostate-specific antigen as a measure of disease outcome in metastatic hormone refractory prostate cancer. J Clin Oncol. 1993;11:607-15. https://doi.org/10.1200/JCO.1993.11.4.607. 